\title{
AUTONOMY OF ELECTRICAL SYSTEMS. TECHNICAL SOLUTIONS BASED ON STORAGE OF ELECTRIC ENERGY
}

\author{
NICOLAE VASILE ${ }^{1}$, BOGDAN TENE ${ }^{2}$, ANDREI NEDELSCHI ${ }^{2}$, NICOLAE FIDEL $^{2}$, IONUȚ CRAIU ${ }^{2}$ \\ ${ }^{1}$ VALAHIA University of Târgoviște, University Professor, ${ }^{2}$ VALAHIA University of Târgoviște, PhD students \\ E-mail: nvasile54@gmail.com
}

\begin{abstract}
The paper deals with the concept of autonomy of electrical systems, which is becoming more and more present, in the context in which the electric-non-electric relation existing on the market is constantly changing in favor of electricity. The factors influencing this trend come from imposing the principles of Sustainable Development, the exhaustiveness of fossil forms of energy, technological advances in the electrical and electronic components industry and their connection with computers. Evolution of Smart Grid, Smart Grid, Smart City, Smart Building, Smart Transport, etc. provides a global electronic system that will power and control most of the economic activity.
\end{abstract}

Keywords: autonomy, electric, storage, energy.

\section{INTRODUCTION}

The autonomy of electrical systems is the main desideratum for the expansion of economic segments based on the use of electricity. The prominence of oil and gas in industrial process energies is explained by the existence of the possibilities of storing these types of resources, which is why a particular priority of the electrical research is to find industrial solutions for the storage of electricity. There are remarkable results that will be presented in this article.

But the autonomy of electrical systems is a wider concept than that, including:

- Existing initial reserves;

- storage capacity;

- saving capacity;

- regeneration capacity;

- recovery capacity.

It also has connections with: decentralized energy production, smart construction, intelligent transport, sustainable mobility, etc.

By type of application, autonomy has two types:

- localization type;

- transport type.

\subsection{Autonomy of localization type}

This refers to applications in a well-defined space and is defined as the percentage of the total energy consumed in the activities carried out in that space, which originated within that location. According to the space to which we refer, we have:

- Global autonomy, which refers to the entire planet, and the approach is similar to the concept of Sustainable Development, Energy [1];

- Continental autonomy, in our case being Europe or, more constrained, by the European Union;

- National autonomy, refers only to a country;

- Local autonomy refers to a locality;

- Neighborhood autonomy, refers to parts of a locality;

- The autonomy of a building, refers to a building that houses several families or an institution;

- The autonomy of a home.

Obviously, the approach from the earth globe to a family is totally different, which is why these types will be treated separately.

\subsection{Autonomy of transport type}

In this case, the situation is more restrictive than in the previous one, given that the bounded space is a means of transport and the initial reserves, storage capacity and all equipment related to saving, regeneration and recovery capacities will be transported in turn, thus increasing the mass and volume of the respective means of transport, thereby contributing to an additional energy consumed. Autonomy of transport type

defines the distance traveled by the transport means to the total energy consumption stored in the storage capacity. There are several categories:

- Autonomy of shipbuilding;

- Autonomy of aeronautical constructions;

- Autonomy of land transport means.

In all the cases listed above, these are the types that are electrically powered.

The article aims at analyzing the methods of electricity storage, which is one of the main tools for sustaining sustainable mobility and sustainable habitat, being part of sustainable development.

\section{TECHNICAL SOLUTIONS BASED ON HYDRAULIC STORAGE OF ELECTRIC ENERGY}

Considering the differences presented above, technical storage solutions differ in localization applications 
compared to transport applications, the latter being more demanding. The article presents an extension of the applications presented in the patent [2], which are at the stage of advertising on the OSIM website.

\subsection{Storage technical solutions for localization type autonomy}

The idea is that the solar and wind energy, which occurs at random times, is captured and transformed into a potential hydraulic form, to be consumed when there are concrete requirements on the part of the beneficiaries [13$15]$.

For very large power applications of tens or even hundreds of MW, some hydrotechnical arrangements (Figure 1) are usually made up of some top-level artificial lakes (3) at a level difference from some surfaces low, marshland (7), which is to be sanitized and where water inlets are arranged (5). By means of a complex motorpump-turbine-generator unit (6), the water from the sockets is pumped into the lake, when the sun and / or the wind blows, and the electric power produced by the solar plant (1), respectively wind (2) trains the pump. In the opposite situation, when there is no sun or wind, the water falls freely from the lake, trains the generator through turbines, producing electricity for consumers. The stored energy is proportional to the volume of circulating water and the level difference.

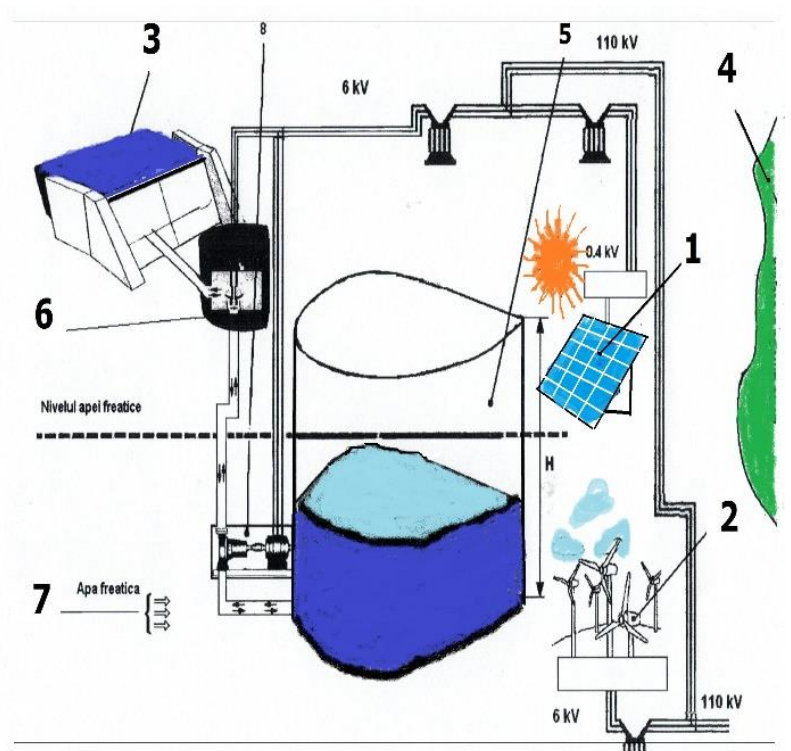

Figure 1. Hydraulic storage with artificial lake and swampy surfaces [2]

Instead of marshy surfaces, there may even be lakes, seas, oceans. There is the idea that all high shores should be equipped with such storage stations along with wind or solar power stations located in the area.

Another variant may be that of (Figure 2) with top-up reservoir (6) and dry ground with some wells at the lower level (4) to increase the level difference and increase the volume of energy stored the rest of the operation being similar.

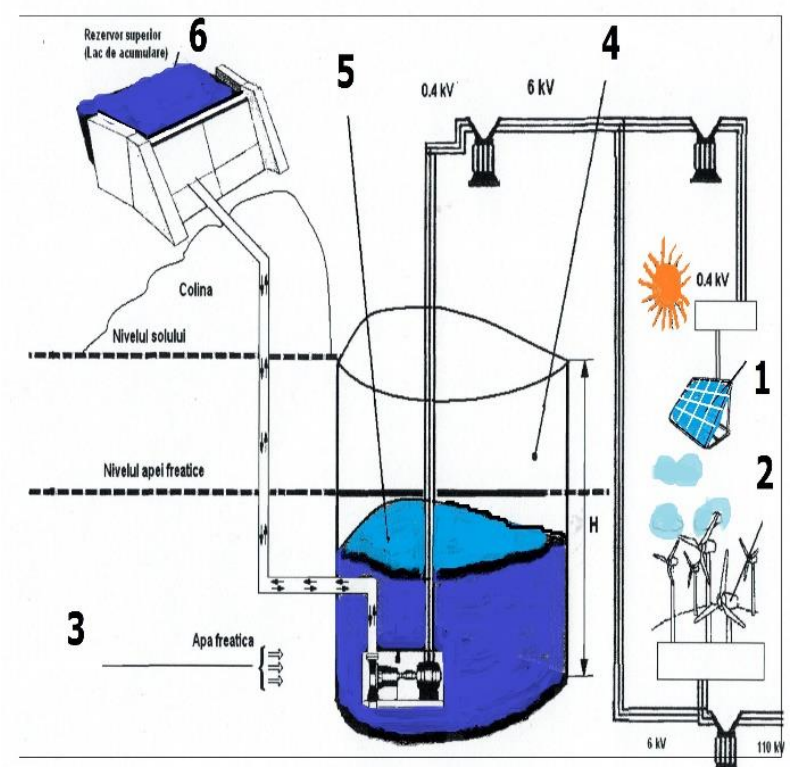

Figure 2. Hydraulic storage with upper reservoir and wells on dry surfaces [2]

Variants with accumulation lake are taken into account in large, national, regional self-employment projects.

There are similar variants where, in the absence of high surfaces, they are replaced by water towers, placed in swampy areas or in the vicinity of lakes, seas or oceans, with low shores (Figure 3).

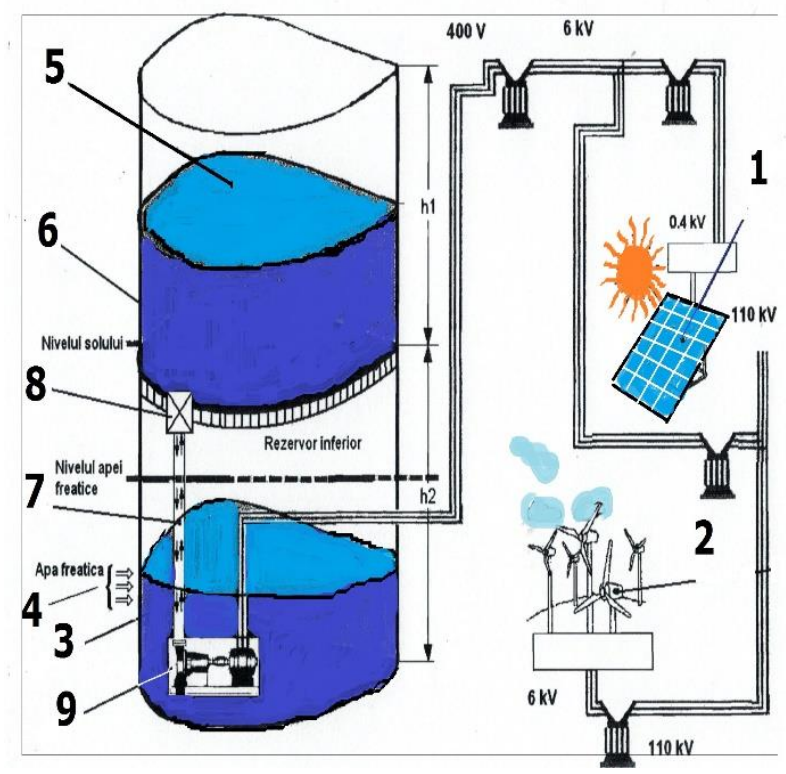

Figure 3. Hydraulic storage with tower on swampy land [2]

The water tower and dry shaft version in dry land (Figure 4) can be practiced wherever we need energy-balanced availability of solar and / or wind power.

Constructive water tower variants are practiced on smaller scale effects, usually at small towns or institutions. 


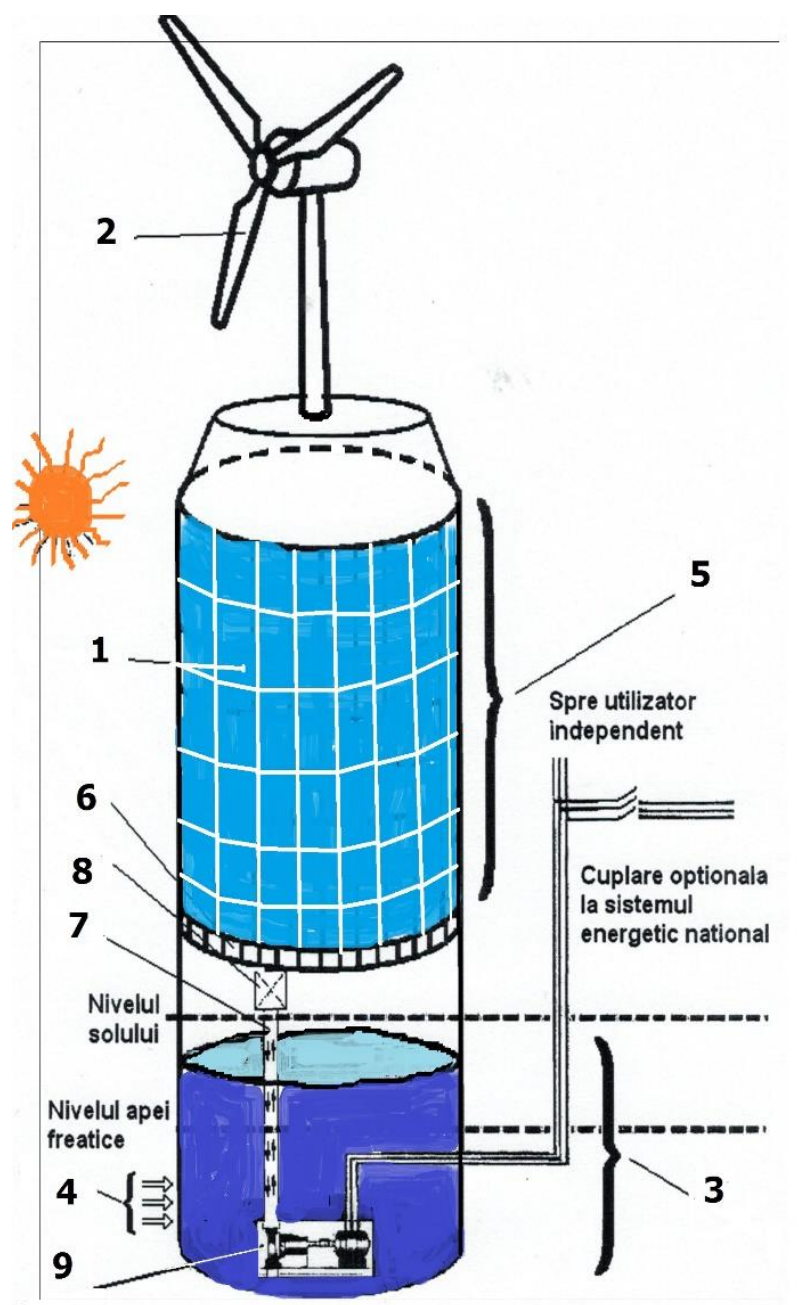

Figure 4. Hydraulic storage with water tower and well [2]

There are small power applications for families, independent farmers, where the tower version turns into a "hourglass building". This is made of light materials, usually plastic, in a symmetrical construction with a top tank and the lower one. Only one is filled with water, after which, coupled with a suitable solar power and / or wind source, a steady, up-down, flow of this water flows as a working fluid, depending on how the sun and / or wind blows. It's a simple way to make the best use of solar and wind energy on a day-night cycle.

\subsection{Technical solutions for storage in the case of naval transport}

Water tower water storage solution naturally applies with great success to high-capacity shipbuilding, very large ships, or those real floating islands that have been built lately.

Here, the vertically-flowing water circuit is made with sea water, pumping in the tower during the sun and / or wind, and generating electricity at the reverse water circuit.

Hydraulic storage currently represents now for more than $90 \%$ of the world market volume.
There are also solutions for storing electricity from renewable sources, using compressed air [4].

\section{TECHNICAL SOLUTIONS BASED ON PHYSICO-CHEMICAL STORAGE OF ELECTRIC ENERGY}

\subsection{Electrochemical batteries}

For medium and small power applications, energy storage is directed to electrochemical solutions. Exxon Mobil, the oil giant, estimates that the evolution of electric batteries is the biggest danger to the oil industry, a conclusion that journalist Steve Coll has reached in the Private Empire book published in 2012 [5].

Tesla, an electric car maker, will invest in a lithium-ion battery "mega fabric" and count on a $30 \%$ price cut [11].

AES Corp has reached 64-megawatt power-based battery power systems located in West Virginia, making it technically competitive compared to hydraulic variants.

An Energy Storage Project led by the Massachusetts Institute of Technology (MIT) proposes a new solution based on liquid-battery batteries [5].

For now, electric batteries offer solutions for autonomous applications such as car, minibus, bus, all electric [10].

A very strong promoter is that Form 1-E has recently been opened for electric cars, showing their competitiveness in the dynamic field, the special accelerations that can be achieved.

\subsection{Nuclear batteries}

For the electric car, but especially for electric air transport, where both AIRBUS and BOEING announced highcapacity electric jets until 2030, it seems that human hope is heading for the nuclear battery [6].

In fact, it is improperly called a battery, because it does not recharge. We can call it the right nuclear source, being a mini nuclear power plant at the bearer. Nor is it an absolute novelty, because the existence of nuclearpowered aircraft carriers and submarines has long been known; the novelty is its miniaturization.

A remarkable result in this field belongs to Roman inventor Adrian Vişan, who worked in France. He recorded one of the first nuclear bacterial patents. He estimated that such a battery could fuel an electric car for about 25 years [8].

I have been involved in trying to make industrial use of this project in Romania. Unfortunately, the project has not been completed [7]. 


\section{ECONOMICAL ISSUES}

The storage of electricity is a problem whose industrial scale depends on the radical change of the world economic system. The oil and gas industry, which is very closely linked to the automotive industry, is based on the fact that all conventional forms of fuel have the possibility of being stored.

Another problem, which always must be solved by the new technical solution, is the price of new technical solutions of the means of transport, especially of their storage capacities. The price of products has a lot to do with the volume of production.

The largest market segments in the field of potential electricity consumers are in the areas of: electric heating and electric cars. If, hypothetically, electricity is entirely switched on and all cars are electric, then the world's electricity demand is a few dozen times greater than current availability, which is not feasible, in a short term. That is why, the solution expected by the specialists is decentralized production and qualitative separation, since for the applications in the field of heating and the electric vehicle, which imply the existence of buffer batteries, there is no need for an energy of the current quality of the energy in the national energy systems. By the similitude, it would be like washing the street with drinkable water.

Charging some batteries can also be done with the power supply from a harmonic source. Such second-energy electricity will be cheaper and can be produced at local, district, institution, farm, family, etc., using local storage forms $[1-9,11,12]$.

\section{CONCLUSIONS}

Hydraulic power storage currently accounts for about $90 \%$ of stored electricity, but physico-chemical storage solutions, which have already reached units of tens of MW, are a hope. Once the problem of storing electricity has been solved, large-scale applications will be unlocked in the automotive and electric heating sectors, which will mean a market opening several times more than current electricity consumption.

\section{REFERENCES}

[1] Vasile, N, Stan, MF: The market of electrical products and technologies. Publishing House Bibliotheca, Târgoviște, 2012. https://www.researchgate.net/publication/27356870 0_Inginerie_electrica_Strategie_Piata_Piata_produs elor_si_tehnologiilor_electrice_Nicolae_Vasile_Mi hail_Florin_Stan_Editura_Bibliotheca_Targoviste_2 012.

[2] Măgureanu, R, Vasile, N, Solar and/or wind power plants with hydraulic energy storage, Patent application: RO 130933 A2 din 21. 08. 2014, published on site-ul OSIM.

[3] Cristescu, C, Dumitrescu, C, Rădoi, R, Dumitrescu,
L: Demonstrative model for energy recovery kinetic rotation in drive equipment hydrostatics, Bulletin AGIR, nr.3, 2014. http://www.agir.ro/buletine/2114.pdf.

[4] Pavel, V, Vădan, I, Bobean, C, Wind system with storing energy in the form of compressed air. National Conference on Theoretical Electrotechnics, SNET 2012, Bucharest. http://www.snet.elth.pub.ro/snet2012/volume/p3.11 .pdf.

[5] http://energyreport.ro/index.php/2013electricitate/2013-stiri-electricitate/2013-energieelectrica/1617-progresul-tehnologiilor-de-stocare-aelectricitatii-ameninta-atat-sistemul-energeticcentralizat-cat-si-industria-de-petrol-si-gaze.

[6] http://ecoprofit.ro/viitorul-masinilor-electrice-stain-bateria-nucleara/.

[7] Vasile, N: Reinventing of human being, Editura Bibliotheca, Târgoviște, 2012.

[8] https://romanians.bc.ca/story/2001/11/inventiaMileniului-III.

[9] Vasile, N, Vasile, F, The technical substantiation economic development of the electric car market, Electrotechnics, Electronics, Automation (EEA), No.4, 2012.

[10] https://www.energy.gov/oe/activities/technologydevelopment/energy-storage.

[11] https://www.tesla.com/powerwall.

[12] http://blogs.worldwatch.org/revolt/unconventional$\%$ e2\%80\%9chydraulic-hydro-storage $\%$ e $2 \% 80 \% 9$ dsystem-offers-energy-storage-for-the-grid-on-agrand-scale/.

[13] https://www.academia.edu/5454718/MODELING _AND_SIMULATION_OF_HYDRAULICENERGY SAVING_SYSTEM_AN_OVERVIEW.

[14] Magureanu, R, Albu, M, Bostan, V ș.a., Optimal operation of Francis Small Hydro turbines with variabiable flow, Conference: Industrial Electronics, 2008. ISIE 2008. IEEE International Symposium, DOI 10.1109/ISIE.2008.4677281.

https://www.researchgate.net/publication/ 224350045_Optimal_operation_of_Francis_Small_ Hydro_turbines_with_variabiable_flow.

[15] Magureanu, R, Kreindler, L, Tudorache, T. ș.a., M FACTS for smart and microgrids applications, Conference: 2016 IEEE PES Innovative Smart Grid Technologies Conference Europe (ISGT- Europe) DOI 10.1109/ISGTEurope.2016.7856291 https://www.researchgate.net/publication/31380288 0_EM_FACTS_for_smart_and_microgrids_applicat ions. 